\title{
Shock Advertising: Not So Shocking Anymore. An Investigation among Generation Y
}

\author{
Brandon Urwin \\ Marike Venter \\ University of the Witwatersrand \\ E-mail: brandonurwin@gmail.com, marike.venter@wits.ac.za
}

Doi:10.5901/mjss.2014.v5n21p203

\begin{abstract}
In today's society, marketers are going to extreme measures to attract consumers' attention in an attempt to break through advertising clutter. A widely used method is shock advertising, however, the effectiveness of this method is questionable. This study aimed to explore the effectiveness of shock advertising on Generation Y consumers in today's society. Three variables were analyzed, namely, level of shock, norm violation and memory recall, with five different types of shock (impropriety, moral offensiveness, sexual references, disgusting images and religious taboos). The moderating effects of these relationships with gender, religion and personal identity were also explored. By means of a quantitative study, 300 university students were asked to complete questionnaires. The overall findings indicated that shock advertising has become obsolete and that marketers need to implement alternative ways of 'breaking through the clutter'. This paper provides marketers with a better understanding of the (in)effectiveness of shock advertising and proposes the importance that marketers should find alternative methods to capture the attention of consumers.
\end{abstract}

Keywords: advertising, shock advertising, type of shock, level of shock, norm violation, memory recall, obsolete, ineffective

\section{Introduction}

Shock advertising has become obsolete, or has it? In today's society, with the increasingly cluttered advertising space, marketers are challenged with the task of breaking through the clutter in an attempt to get their respective brand noticed (Dahl, Frankenberger \& Manchanda, 2003). As a result, marketers are using shock advertising (Coyler, 2002). Advertisements are considered offensive or "shocking" when they violate personal and societal norms and values, regardless of whether it is because of being sexually inappropriate, indecent, vulgar or aesthetically unappealing (Dahl, et al., 2003).

Although shock advertising is effective and possibly leads to increased brand awareness and an increase in sales volume (Waller, 2004), shock advertising might alienate consumers and create disgust towards the brand which could lead to brand boycotts (Klara, 2012; Hodge, 2007). Klara (2012) is of the opinion that shock advertising has been "done to death", already by the late 1980s. In agreement with this statement, Lightfoot, Lilley \& Kavanagh (2006) state that although shock advertising is ubiquitous, whether in movies, on television or advertisements, it is losing its shock value and thus is no longer as controversial as it used to be. Dahl, et al. (2003) mention that shock advertising has become commonplace when advertising a new product or brand, therefore it questions whether shock advertising is as unique and "clutter-breaking" as marketers assume it to be. The other side of this concept of ineffectiveness is evident in Andersson, Hedelin, Nilsson \& Welander's (2004) study where an advertisement may be too shocking and create a negative image of the brand in the consumer's mind which can lead to a loss in sales. Sandıkcı (2011) states that although shock advertisements may create awareness for a brand or product, the long-term effect of shock advertisements is still unknown. As a result, the effectiveness of shock advertising has become questionable (MacDonald, 2008).

The aim of this study was therefore to ascertain whether shock adverting is indeed losing its "shock" and becoming obsolete and ineffective. Further, this study had three objectives: The first objective was to assess the influence of level of shock, norm violation and memory recall on the ineffectiveness of shock advertising. Secondly, to determine the moderating effects of gender, religion and personal identity on the obsoleteness of shock advertising. And lastly, to provide marketers with a better understanding of the ineffectiveness of shock advertising and emphasize the importance of alternative methods for breaking through the advertising clutter.

This study looked at members of Generation Y; those according to Kapner (1997), Duff (1999) and Neuborn \& 
Kerwin (1999) who were born between 1979 and 1994. Generation Y typically responds better to irony, humour and the truth without manipulation or unrealistic depiction (which Shock Advertising may sometimes appear to do the contrary) (Wolburg \& Pokrywczynski, 2001). Wolburg \& Pokrywczynski (2001) go on to say that this generation of people is often known as the elusive youth market with descriptions such as technologically clever, individualistic and sophisticated (Valentine \& Powers, 2013). They have also been described as a market who is not as brand loyal as previous generations and are skeptical of traditional methods of advertising. Messages need to be quick, honest and direct (Pesquera, 2005) and people of this group value the opinions of friends and word-of-mouth more than advertising media when making a purchasing decision (Peterson, 2004). Generation $Y$ is a valuable segment to business and marketers for a number of reasons: (1) the size of the market is great, (2) students at this age are trendsetters for future generations as well as peers, (3) they are able to influence their parents in terms of purchases and (4) this age (especially students) are expected to lead a high standard of living with salaries that can afford high-end products (Wolburg \& Pokrywczynski, 2001).

The question is raised as to whether looking at these factors if an advertising method such as Shock Advertising can appeal to Generation Y.

\section{Theoretical Background}

\subsection{Shock Advertising}

There are several definitions of shock advertising. For the purpose of this paper, shock advertising is defined as the use of intentional, offensive, controversial and attention grabbing advertising used to sell a particular product or idea (Pickton \& Broderick, 2005; Castellon, 2006). Derived from this definition, there are seven types of shock appeals that marketers can use to shock the audience (Dahl, et al., 2003):

- Disgusting images that include images containing blood, gore, body parts, orifices, disease, parasites, death or bodily harm.

- Sexual references to masturbation, nudity or sexual acts.

- Profanity/obscenity that makes use of swear words, rude gestures or racial epitaphs.

- Vulgarity applies to pictures/acts that are distasteful, lack sophistication and are crude, for example, farting or nose picking.

- Impropriety or indecency, in other words a violation of social decency and etiquette.

- Moral offensiveness where images depict innocent people or animals being harmed, uncalled for violence or sex, using people that provoke violence (for example, Hitler), unfair behaviour or using children in uncomfortable situations.

- Religious taboos where marketers make use of religious or spiritual symbols or people inappropriately.

There are a number of variables that influence the effectiveness of a shocking advertisement. These variables, namely level of shock, norm violation and memory recall, allow a marketer to measure the effectiveness or ineffectiveness of an advertisement.

\subsubsection{Level of shock}

Level of shock can be described using a scale ranging from high to low. It is most accurately described by Huhmann \& Mott-Stenerson (2008) where a controversial advertisement which is too low in perceived shock value or offensiveness will not likely be sufficiently engaging to accomplish brand-processing goals. The shock value may not be offensive or shocking at all because of its ubiquity (Lightfoot, et al., 2006). Alternatively, a shock advertisement that has a high perceived shock value or offensiveness can lead to the consumer becoming upset or disgusted (Klara, 2012). This disgust would lead consumers to actively ignore the advertisement in order to reduce their discomfort, thus detracting from the brand and its product (Andersson, et al., 2004).

\subsubsection{Norm violation}

According to Dahl, et al. (2003), norm violation can be defined as the breach of shared expectations that people develop through the process of social learning. As people interact and form societal groups, they begin to learn what that group defines as acceptable and unacceptable behavior (Baron \& Byrne, 1977). This range of defined acceptable and 
unacceptable behavior is used to evaluate objects, ideas, actions, persons, or in this case, advertisements (Sherif \& Sherif, 1969). If a shock advertisement falls within these norms, and does not contravene society's perception of good behaviour, then societal norms have not been violated (Dahl, et al., 2003). Advertising violates these societal norms and is considered offensive when the content breaks the norms of good taste, decency, visual decency and personal moral standards (Dahl, et al., 2003; Day, 1991). Manceau \& Tissier-Desbordes (2006) have shown that consumers have felt embarrassment, discomfort and in some cases, mental disturbance, when being exposed to shock advertisements. Consumers have also felt the feelings of guilt and shame after being exposed to these advertisements and having felt their norms have been violated (Sabri, 2012; Keltner \& Buswell, 1997; Eisenberg, 2000; Heywood, 2002). Dubreuil (2010) writes that if a person's norms are violated, they may have a feeling of righteous anger and indignation (anger or annoyance provoked by a perception of unfair treatment) in response to this violation. If an advertisement forces a consumer to feel anger, then it has violated their norms. These feelings are also said to induce the desire to hurt, injure or blame the object/person responsible for the violation, for example in the case of shock advertising, it may be the desire to boycott the product (Fessler \& Hayley, 2003).

\subsubsection{Memory recall}

A principle measure of communication and advertisement effectiveness is recall of commercial content (Heath \& Nairn, 2005). Bagozzi \& Silk (2001) define recall as the mental reproduction of a target object, item or advertisement that a consumer has previously seen or experienced. People need to be able to remember the brand as well as the message being advertised in order for the advertisement to be effective (Bushman \& Phillips, 2001). Memory is a crucial component in determining how consumers respond to advertising, including whether to purchase the product in question or not (Bushman \& Bonacci, 2002). In the case of norm violation, consumers can feel anger towards an advertisement. According to Bushman \& Phillips (2001), anger might impair memory for the following three reasons: Firstly, negative moods (not exclusively anger) interfere with the brain's encoding of information (Ellis, Thomas \& Rodriguez, 1984). Secondly, mental rehearsal of the advertisements might be interfered with because of the aggressive thoughts of people who feel angry after seeing an advertisement (Berkowitz, 1984). And lastly, angry consumers may try to remedy or repair their bad mood, which takes a lot of effort and detracts them from being able to remember the advertisement (Morris \& Reilly, 1987). Bushman \& Bonacci (2002) state that even though consumers are exposed to a multitude of advertisements daily, they are not able to remember of all of them. People may not remember an advertisement because they did not encode it (encoding failure) or because they did encode it but are unable to retrieve it later (retrieval failure). Depending on how meaningful the information is to the consumer, it will determine how easily, or if at all, consumers will be able to retrieve the information from memory (Kahneman, 1973). Hunt \& Ellis (1999) go on to say that if information is not reinforced or leaves a lasting impression on consumers, it will lead to retrieval failure. Research has shown that television advertisements with violent content are less memorable than advertisements without violent content (Söderlund \& Dahlén, 2010; Bushman, 2007). Although sexual content may appeal to audiences, brand recall is poorer for sexual advertisements than for neutral advertisements, especially for women and people who are uncomfortable with sex (Alden \& Crowley, 1995; De Pelsmacker \& Geuens, 1996; Jones, Stanaland \& Gelb, 1998).

\subsubsection{The Outcome: Obsolete and Ineffective}

According to Merriam-Webster (2013), obsolete can be defined as no longer in use or no longer useful. If, for example, an advertisement is obsolete, it can be described as out of date and no longer effective as there are better alternatives in the business environment (Oxford University Press, 2013). If an advertisement is ineffective, Merriam-Webster (2013) and Oxford University Press (2013) both define it as not creating the desired effect or an effect that is intended or significant. As stated by Heath \& Feldwick (2008), the goal of advertising is to enhance the favourability of the brand and create a positive attitude in the minds of consumers. Therefore, by applying the definitions of 'obsolete' and 'ineffective', if an advertisement is no longer useful or creating the desired effect of enhancing the favourability of the brand, it can be considered to be obsolete and ineffective. An advertisement can be considered obsolete and ineffective in two scenarios, namely, the advertisement is too shocking or the advertisement is not shocking enough. These concepts are explained in more detail in the next section.

\subsubsection{The advertisement is too shocking}

If an advertisement is perceived to be too offensive or shocking, it is ineffective in the sense that it will lead to a negative 
impression towards the product or brand, and thus not lead to sales. One of the biggest risks a firm takes in using shock advertising is that it can alienate its consumers and create a negative image in the minds of consumers (Klara, 2012). This can lead to a decrease in sales for the firm, as Hodge (2007) mentions with the case of French Connection UK (FCUK). When FCUK released an advertisement with two ladies intimately kissing each other, they saw their share price drop dramatically in the United Kingdom (Hodge, 2007). If an advertisement is too shocking, consumers may deliberately avoid what the firm is saying for example, looking away or changing the channel (Williams, 2009). Williams (2009) goes on to explain that if firms begin to add unnecessary layers of shock and violence, consumers may see through it, and see it as a ploy only to attract attention and they may feel as if they are being manipulated (Sandıkcı, 2011). Harrison (2011) and Williams (2009) both emphasise the notions of guilt and the "I'm not that bad" mentality in showing the ineffectiveness of shock advertising.

In previous cases (Tilles, 1998; Thirteen complaints, 1999; Wong, 2008; Schwartz, 2001) where consumers were so offended by particular advertisements, pressure was put on advertisers to change their campaigns, on media to stop accepting the advertisements and on other consumers to boycott the product and/or company. Although these advertisements may attract attention and break through the clutter, they may damage a firm's image and customer base and may not lead to product purchase (Prendergast, Ho \& Phau, 2002). In a study performed by Andersson et al. (2004), both male and female respondents had an overall negative reaction towards advertisements containing excessive violence and sex (and in turn, the product/brand) and did not understand what the advertisement was trying to promote. A negative impression causes consumers not to support the brand and will therefore have no intent to purchase the product (Andersson, et al., 2004). In Chan, Li, Diehl \& Terlutter (2007), it was evidenced that offensive advertisements can be harmful to products and brands. The more negative the impression, the more likely consumers will reject the brand or product. These negative perceptions also lead to low-purchase intention (Chan et al., 2007). Consumers are less likely to buy products from a brand who uses offensive advertisements if similar products are available from a firm who does not make use of this type of advertising (An \& Kim, 2006).

\subsubsection{The advertisement is not shocking enough}

The other way an advertisement can be considered obsolete and ineffective is if the advertisement has not broken through the clutter, violated societal norms, reached the consumer or left a lasting impression. Huhmann \& MottStenerson (2008) mention that a controversial advertisement with too low a perceived offensiveness or shock value will not likely be sufficiently engaging to accomplish brand-processing goals. Controversial advertisements wear out with repetition, even if it is for a different product or brand, there is the mentality of seen it once, seen it enough (Huhmann \& Mott-Stenerson, 2008). In other words, perhaps the first time a controversial concept was shown to the public, there was a reaction, but thereafter the perceived level of shock consistently decreased (Huhmann \& Mott-Stenerson, 2008; Williams, 2009). The public have heard about all the problems that shock advertisements portray before, and therefore it has become easier for consumers to ignore these advertisements (Williams, 2009).

Shock has become ubiquitous (Klara, 2012; Lightfoot, et al., 2006). Jarlbro (1994) explains that the reason why consumers do not react to offensive advertising is that they are used to violence and sex from films and television. Consumers remain unmoved and no longer pay attention to these advertisements (MacDonald, 2008). Offensive advertising no longer violates consumers' norms as described in Dahl et al. (2003) and therefore no longer breaks through the clutter to leave a lasting impression on the consumer. According to Sandıkcı (2011), in today's post-modern world, consumers are becoming more knowledgeable with regards to advertising. They possess more advertising savvy and it becomes harder to grab the attention of these consumers. The power shifts to the consumer as to whether they want to accept or reject an advertisement and in turn, a product or brand. Consumers are starting to see through the shock and might see it as a gimmick to just get attention for the brand. As Marketing Week (2002) discussed, what may be shocking today, may be commonplace tomorrow. Klara (2012) goes on to say that shock advertising has been 'done to death' by the ' 80 s and has lost its effectiveness in making consumers feel uncomfortable (Javed \& Zeb, 2011). Finlay MacDonald (2008) describes this concept as 'shock fatigue'; consumers have been exposed to so much violence and sex in their lives through older shock advertisements and other forms of media such as television and graphic novels, that shock advertisements no longer have that "shock" factor. This describes the notion that consumers have seen it all before, there is nothing new and therefore there is no shock value based on their preconceived norms and values.

\section{Conceptual Framework and Research Hypotheses}

Based on the research accumulated, the following model was conceptualized (See Figure 1). 
Figure 1: Conceptual Model

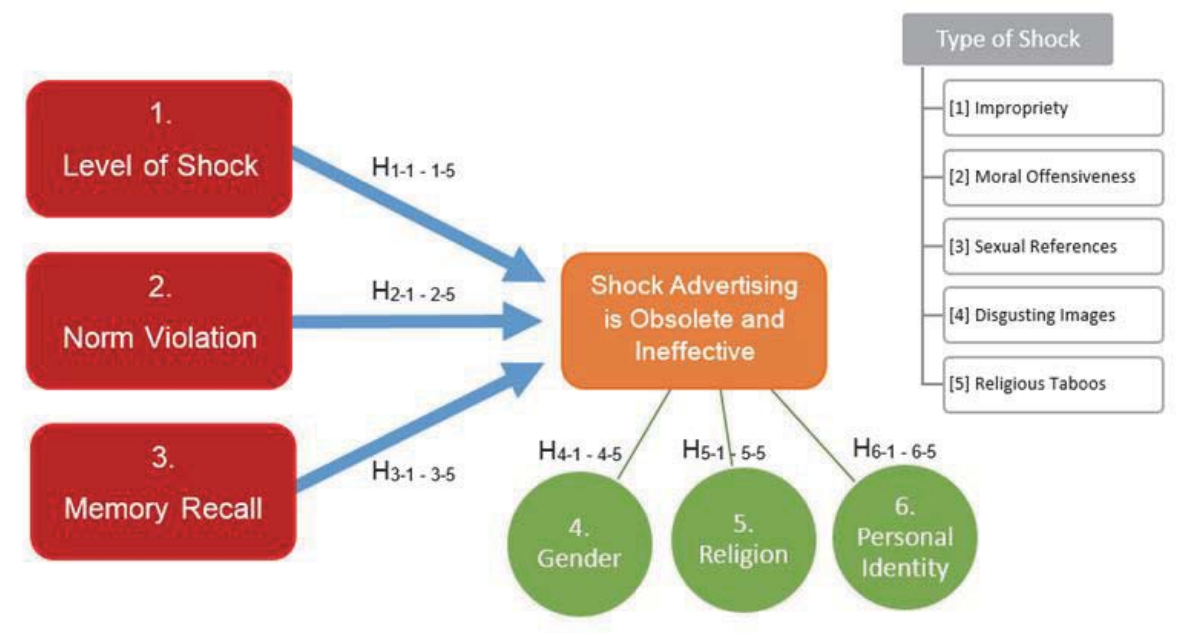

In Figure 1 (above), 1) Level of Shock, 2) Norm Violation, and 3) Memory Recall indicate the variables that influence whether shock advertising is obsolete and ineffective, in other words, the outcome. The circles (4-6) are the moderator variables of gender, religion and personal identity, which were tested for any significant difference between the factors within these moderators. The 'type of shock' block indicates that each variable (1-3) and moderator (4-6) which was tested against the outcome, was performed for five different advertisements representing the five types of shock used. For this research, there were six categories of hypotheses where each hypothesis was tested on the various advertisements of (1) Impropriety, (2) Moral Offensiveness, (3) Sexual References, (4) Disgusting Images and (5) Religious Taboos. The proposed hypotheses were as follows:

$\boldsymbol{H}_{1-(1-5):}$ In terms of the advertisement, Level of shock has a significant influence on the Ineffectiveness of Shock Advertising.

$H_{2-(1-5):}$ In terms of the advertisement, Norm violation has a significant influence on the Ineffectiveness of Shock Advertising.

$H_{3-(1-5):}$ In terms of the advertisement, Memory recall has a significant interaction on the Ineffectiveness of Shock Advertising.

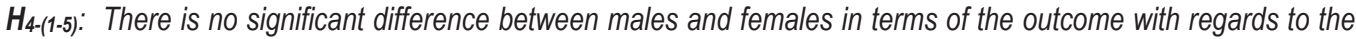
specific advertisement used.

$H_{5-(1-5):}$ There is no significant difference between the different religions in terms of the outcome with regards to the specific advertisement used.

$H_{6-(1-5):}$ There is no significant difference between the identities of consumers in terms of the outcome with regards to the specific advertisement used.

\section{Research Design and Methodology}

Both secondary and primary data were collected. Secondary sources such as textbooks and journal databases (JSTOR, EBSCOHost) were used. The primary research followed a conclusive, descriptive design approach that tested the proposed hypotheses in the context of this paper, namely shock advertising (Malhotra \& Birks, 2006). Further, a single cross-sectional design was done with only one sample being drawn and used for the purpose of this study. The population consisted of Johannesburg-based students between the ages of 18 and 25 , with the conveniently drawn sample being 300 students from the University of the Witwatersrand.

Due to the sensitive nature of the subject matter, ethics was of major importance and clearance was obtained before the study commenced. Students were asked to complete a questionnaire that consisted of three sections: Section A comprised of questions related to five advertisements that respectively tested impropriety, moral offensiveness, sexual references, disgusting images and religious taboos. Fictional brands were used as to remove any preconceived ideas of 
brand names. The five advertisements used were:

a) Advertisement 1: Tampan (See Figure 2) falls under 'Impropriety' (as stated by Dahl, Frankenberger \& Manchanda, 2003) as it violates social conventions. Women's menstruation is not a publicized event but is considered a private matter of women. In this advertisement, menstruation is almost made fun of as the woman has a large smile on her face and the use of blood is over exaggerated. The message is that if you use that particular brand of tampon, a woman will be able to prevent the situation depicted.

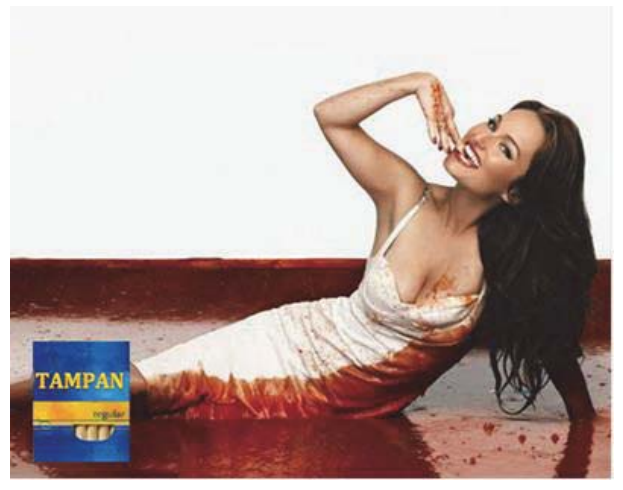

Figure 2: Advertisement 1: Tampan (Impropriety)

b) Figure 3 (Advertisement 2: Nkosi Children Home) indicates an advertisement that makes use of 'Moral Offensiveness' (Dahl, et al., 2003) and depicts infants suckling from a pig with the tagline 'If you don't feed them, who will?' This advertisement puts children in a situation where the viewer feels uncomfortable. It is morally offensive and makes use of unfair or improper behavior as this is not a normal situation for infants, as they should rather be feeding from their mothers as opposed to a farm animal. This advertisement aims to get across a message that if parents, or a Children Home, are unable to care for infants, they would have to resort to other sources for comfort and food.

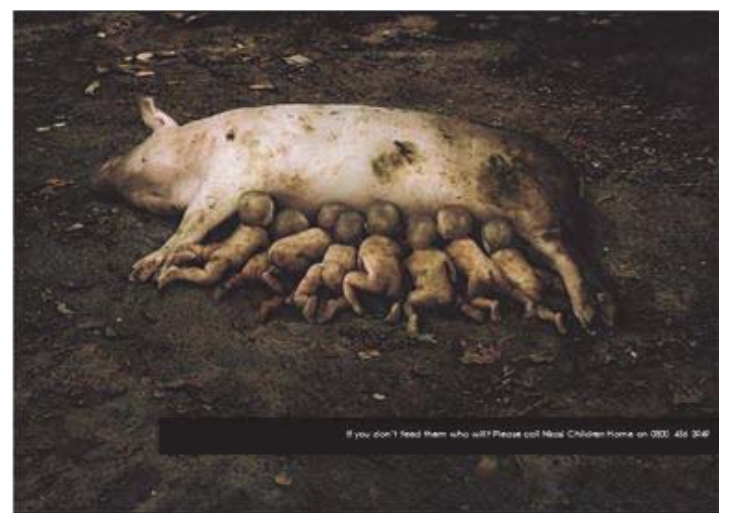

Figure 3: Advertisement 2: Nkosi Children Home (Moral Offensiveness)

c) Figure 4 (Advertisement 3: Prestige) presents an advertisement that represents 'Sexual References' (Dahl, et al., 2003). Prestige is a fictional clothing brand specialising in tailor-made men suits. The advertisement in Figure 4 depicts a woman lying on a car wearing only her underwear, with a tie wrapped around her neck that is held by a man wearing Prestige clothing. This imagery used in the advertisement implies that the man has sexual control or dominance over the woman, and it may even depict rape or abuse of the woman. 


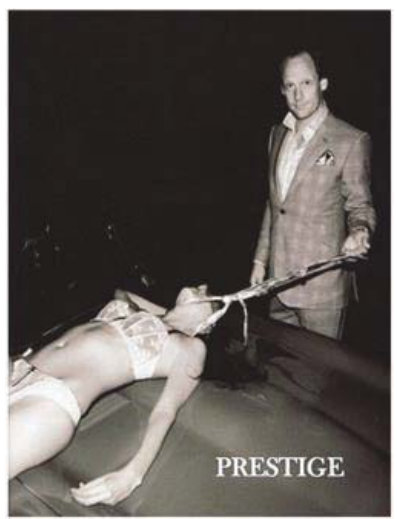

Figure 4: Advertisement 3: Prestige (Sexual References)

d) In Figure 5 (Advertisement 4: Saber), the advertisement makes use of 'Disgusting Images' (Dahl, et al., 2003). It contains images of blood, harm to the body and death. This advertisement in Figure 5 shows a man being stabbed to death using a set of Saber knives, implying their sharpness and quality. This is not the normal setting for a knife advertisement, as they are normally shown cutting food or wood or steal (to show their durability and sharpness).

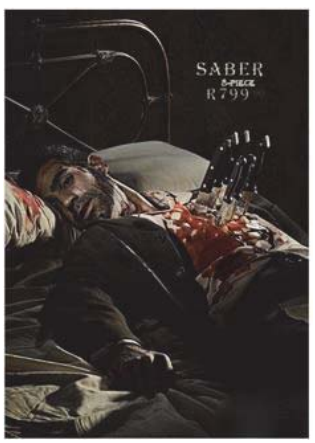

Figure 5: Advertisement 4: Saber (Disgusting Images)

e) The final advertisement (Figure 6: Advertisement 5: Avantgarde) makes use of 'Religious Taboos' which includes an inappropriate use of spiritual or religious people (Dahl, et al., 2003). In this clothing advertisement, the Pope of the Roman Catholic Church is seen kissing the Sheikh of the Al-Azhar Mosque. This is inappropriate because (1) it two men kissing which is seen as homosexuality, which is condemned and (2) it is two different religions (with opposing views) who are now kissing each other as if they are lovers and friends.

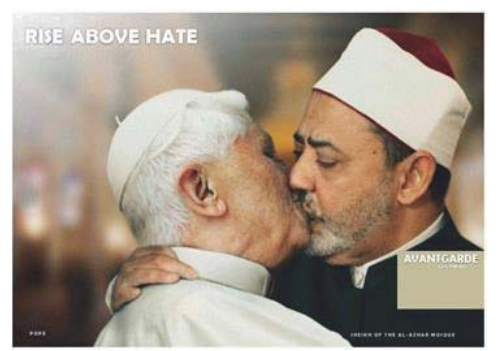

Figure 6: Advertisement 5: Avantgarde (Religious Taboos) 


\subsection{Measurement Instrument Development}

Question 1 asked questions regarding level of shock adapted from the Viewer Response Profile (VRP) developed by Schlinger in 1979. The outcome (ineffectiveness) was tested in Question 2 using scales of attitudes developed by Voss, Spangenberg \& Grohmann (2003). Finally, Questions 3 and 4 tested norm violation using scales adapted from Watson, Clark \& Tellegen (1988), Edell \& Burke (1987) and Puto \& Wells (1984). Both negative and neutral feelings were questioned with regards to norm violation for each advertisement.

Section B consisted of questions related to demographics and included age, gender, how the participant identified themselves and what their religious affiliation was. And Section $C$ tested memory recall with scales adapted from Söderlund \& Dahlén (2010) and Bushman (2007). The responses were categorized as follows: to test memory recall, answers were categorized by (1) the brand and imagery are remembered, (2) only the brand is remembered, (3) only the imagery is remembered, (4) only the product is remembered and (5) nothing is remembered; (1) yes and (2) no was used to test whether a respondent wanted to forget an advertisement on purpose as well as when they were asked if there were any advertisements they were unable to recall.

In terms of administering and gathering questionnaires, a set procedure was followed through. Firstly, set presentation times were arranged with the lecturer beforehand in order for permission to be obtained. A slideshow presentation accompanied the administering of questionnaires. Once each student had a questionnaire, the presentation began and each advertisement was shown to respondents via the projector as they worked through Section A. By making use of the projector, as opposed to having the advertisements printed on the questionnaire, allowed the images to be large and clear. Also, when moving on to Section C: memory recall, the images on the projector were no longer visible. If the advertisements were printed out, it could lead people to refer back to them therefore removing the element of memory recall. This process was continued and various lectures were used until the required number of completed questionnaires had been obtained. Once the completed questionnaires were collected, the data was coded and captured using Microsoft Excel and then transferred into SAS Enterprise Guide 5.1 where the data was analysed.

\section{Data Analysis and Results}

Firstly, the descriptive statistics were analysed: the sample $(n=300)$ that was obtained had an average age of 21.66 years. Sixty eight percent of the respondents were female compared to $32 \%$ of which were male. Fourty seven percent of the respondents identified themselves as Black, while the remainder consisted of Whites, Indians and Coloureds.

In terms of memory recall, for Advertisements 1, 3 and 4, the majority of participants (39.67\%, 50.33\% and 39.33\% respectively) did not remember anything about the advertisement. For advertisements 2 and 5, the majority of respondents were only able to remember the imagery in the advertisement (e.g. blood, girl in blood, two gay men, religious leaders kissing) with $41.33 \%$ and $41.67 \%$ of the sample respectively. Between $25 \%$ and $47.33 \%$ of the sample indicated they wanted to purposefully forget the advertisements with Advertisement 5 being the highest (47.33\%).

In terms of the outcome, sexual references (Advertisement 3) was described as the most dull, unenjoyable and ineffective advertisement with mean values of 2.42, 1.95 and 2.07 respectively. Advertisement 4 (disgusting images) was considered the most unpleasant advertisement. With an average of 2.314 across all averages, overall all these advertisements leaned towards the ineffective or negative side of this scale. Reverse coding was performed on particular questions for each advertisement as they were expected to score high on 1 (on the Likert scale). As memory recall made use of categorical questions, checks for reliability and validity were not performed on these questions.

The statistical software, SAS Enterprise Guide 5.1, was used to perform analyses on the data. With regards to reliability, Cronbach Alphas ranged from 0.62 and 0.91 indicating reliability in all the questions and in turn, the variables of the model. A factor analysis was performed to ensure validity of the data. It was found that all relevant variables load onto one factor with the exception of attitudes towards the advertisements. It was found that negative feelings (disgusted, uncomfortable, insulted, irritated, resistant and offended) loaded onto one factor and neutral feelings (unaffected, unmoved, disinterested, indifferent and bored) loaded onto another.

Single linear regression was used to test the relationships between level of shock and norm violation with the outcome variable (ineffectiveness). With a $5 \%$ level of significance, level of shock and norm violation respectively both have a significant influence on the ineffectiveness of shock advertising with regards to all five types of shock used. In terms of memory recall, there is no significant interaction on the outcome with regards to the five types of shock.

A two-way ANOVA was used to test memory recall on the outcome and one-way ANOVAs were used to test for any significant difference between gender, personal identification and religion. There is no significant difference in terms of gender on the ineffectiveness of shock advertising except with religious taboos. Religion has no significant difference in 
terms of the outcome except with sexual references. The impact of personal identity has no significant difference with regards to moral offensiveness and sexual references. In terms of impropriety, disgusting images and religious taboos, there is a significant difference in terms of ineffectiveness between the different personal identities of respondents. Figure 7 shows a summary of all the hypotheses and their respective p-values and whether the results were found to be significant or not.

Figure 7: Table 1: Hypotheses Testing Summary

\begin{tabular}{|c|c|c|c|c|}
\hline Variable & Type of Shock & Hypothesis & P-value & Significant/Non-significant \\
\hline \multirow{5}{*}{ 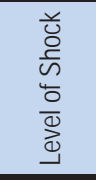 } & Impropriety & $\mathrm{H}_{1-1}$ & $<0.0001^{\star}$ & Significant \\
\hline & Moral Offensiveness & $\mathrm{H}_{1-2}$ & $<0.0001^{*}$ & Significant \\
\hline & Sexual References & $\mathrm{H}_{1-3}$ & $<0.0001^{*}$ & Significant \\
\hline & Disgusting Images & $\mathrm{H}_{1-4}$ & $<0.0001^{*}$ & Significant \\
\hline & Religious Taboos & $\mathrm{H}_{1.5}$ & $<0.0001^{*}$ & Significant \\
\hline \multirow{5}{*}{ 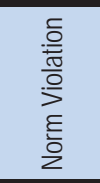 } & Impropriety & $\mathrm{H}_{2-1}$ & $<0.0001^{*}$ & Significant \\
\hline & Moral Offensiveness & $\mathrm{H}_{2-2}$ & $<0.0001^{\star}$ & Significant \\
\hline & Sexual References & $\mathrm{H}_{2 \cdot 3}$ & $<0.0001^{*}$ & Significant \\
\hline & Disgusting Images & $\mathrm{H}_{2-4}$ & $<0.0001^{*}$ & Significant \\
\hline & Religious Taboos & $\mathrm{H}_{2.5}$ & $<0.0001^{*}$ & Significant \\
\hline \multirow{5}{*}{$\begin{array}{l}\overline{\bar{J}} \\
\mathbb{d} \\
\alpha \\
\Sigma \\
\overline{0} \\
\bar{E} \\
\Sigma\end{array}$} & Impropriety & $H_{3-1}$ & 0.6590 & Non-significant \\
\hline & Moral Offensiveness & $\mathrm{H}_{3-2}$ & 0.8970 & Non-significant \\
\hline & Sexual References & $\mathrm{H}_{3-3}$ & 0.4969 & Non-significant \\
\hline & Disgusting Images & $\mathrm{H}_{3-4}$ & 0.0799 & Non-significant \\
\hline & Religious Taboos & $\mathrm{H}_{3-5}$ & 0.4392 & Non-significant \\
\hline \multirow{5}{*}{ 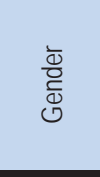 } & Impropriety & $\mathrm{H}_{4 \cdot 1}$ & 0.1621 & Non-significant \\
\hline & Moral Offensiveness & $\mathrm{H}_{4.2}$ & 0.4909 & Non-significant \\
\hline & Sexual References & $\mathrm{H}_{4 \cdot 3}$ & 0.1792 & Non-significant \\
\hline & Disgusting Images & $\mathrm{H}_{4-4}$ & 0.5588 & Non-significant \\
\hline & Religious Taboos & $\mathrm{H}_{4.5}$ & $0.0067^{*}$ & Significant \\
\hline \multirow{5}{*}{ 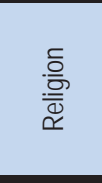 } & Impropriety & $H_{5-1}$ & 0.9156 & Non-significant \\
\hline & Moral Offensiveness & $\mathrm{H}_{5-2}$ & 0.4234 & Non-significant \\
\hline & Sexual References & $\mathrm{H}_{5-3}$ & $0.0464^{*}$ & Significant \\
\hline & Disgusting Images & $H_{5-4}$ & 0.1630 & Non-significant \\
\hline & Religious Taboos & $H_{5.5}$ & 0.4702 & Non-significant \\
\hline \multirow{5}{*}{ 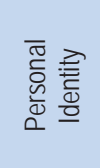 } & Impropriety & $H_{6-1}$ & $0.0127^{*}$ & Significant \\
\hline & Moral Offensiveness & $H_{6-2}$ & 0.1333 & Non-significant \\
\hline & Sexual References & $\mathrm{H}_{6-3}$ & 0.1663 & Non-significant \\
\hline & Disgusting Images & $\mathrm{H}_{6-4}$ & $0.0001^{*}$ & Significant \\
\hline & Religious Taboos & $\mathrm{H}_{6.5}$ & $0.0083^{*}$ & Significant \\
\hline
\end{tabular}

\section{Discussion of Results}

In terms of the descriptive data, the majority of respondents for each type of shock either did not remember anything about the advertisement or only remembered the imagery. Therefore, the advertisement was unable to imprint the brand into the consumer but the imagery instead, overpowered the rest of the content. Further, it was evident that consumers found sexual advertisements the most ineffective as compared to the other four types used in this study. With regards to demographic data, there were a number of variations in the results. When determining the ineffectiveness of shock advertising, there was a difference in the opinions between genders, religions and personal identity.

Further, the first variable, level of shock, did have an influence and contributed positively towards a shock advertisement being considered ineffective. In terms of the outcome variable, ineffectiveness was classified as dull, unpleasant, unenjoyably and most importantly, ineffective. Norm violation followed a similar pattern to that of level of shock, where for all five advertisements, it was found that norm violation influenced the outcome variable, namely ineffectiveness. Therefore, when considering the ineffectiveness of shock advertising, marketers need to look at how both level of shock and norm violation contribute towards the advertisement, irrespective of the type of shock present. This same result was expected for the third variable, memory recall. However, the opposite was found. There was no significant interaction between memory recall (and its two categorical factors) and shock advertising being considered 
ineffective. This means that memory recall does not influence ineffectiveness, in other words, whether people remember an advertisement or not makes no difference to the ineffectiveness of a shock advertisement.

Results showed that for impropriety, moral offensiveness, sexual references and disgusting images there was no significant difference in the outcome of ineffectiveness when compared between males and females. However, there was a significant difference in terms of the outcome with regards to advertisements which make use of religious taboos. It was found that there is no significant difference in terms of religious affiliation of participants when it came to advertisements containing impropriety, moral offensiveness, disgusting images and religious taboos. For advertisements containing sexual references, the difference among religions was significant with a particular difference between Muslim and Jewish consumers. In terms of personal identity, it was found that there is a difference among the identities in relation to the outcome of ineffectiveness with advertisements making use of impropriety, disgusting images and religious taboos. Specific differences were identified for the disgusting images-type advertisement between (1) Black and Asian participants, (2) Indian and Asian participants, (3) White and Asian participants and lastly (4) White and Coloured participants. It appears that Asian participants seem to have differing views when it comes to disgusting images as compared to the rest of the categories. Advertisements containing morally offensive images or sexual references had no difference in terms of personal identity and the outcome.

\section{Implications for Marketers}

Marketers must be made aware that level of shock and norm violation both contribute towards the ineffectiveness of this type of advertising. Type of shock, generally, appears to make no difference in terms of the outcome, as five types were tested, and in terms of the variables, had similar outcomes. Memory recall does not have an effect, as it makes no difference whether an advertisement is remembered or not, it does not contribute or detract from the ineffectiveness of the advertisement. In terms of the results shown above, in general, no matter what gender, personal identity or religion, shock advertising appears to be ineffective, dull, unenjoyable and unpleasant. Marketers need to be made aware of this as shock advertising may no longer be living up to its name. If indeed shock advertising can be seen as ineffective, then firms may need to look for new areas of advertising that are able to break through the myriad of current advertising to make a positive connection with consumers. As seen from the above descriptive statistics, people either do not remember anything at all with regards to the advertisement or only remember the imagery displayed. This does not contribute positively towards a firm's advertising because consumers are unable to remember the brand in question. Participants either answered the questionnaire in terms of the advertisement being too graphic and thus in turn violating their norms and causing them to have a negative opinion towards the brand or they answered it on the opposite end of the scale. A number of participants answered the questionnaire where the advertisements appeared dull and nothing out of the ordinary. Both these views can be termed ineffective. Marketers need to begin to realise that investing time, money and effort into shock advertising may not be as valuable as it appears. Shock advertising is deemed to be ineffective and therefore firms need to begin using more effective alternatives which will not harm the brand.

\section{Contributions of this Study}

This study contributes to academic literature and market place knowledge in numerous ways. This research paper is a beginning to fully understanding the concept of shock advertising, with the provision and allowance of future research. This paper provides a basic understanding of shock advertising as well as its effectiveness, or in this case, lack thereof, to academics and firms. It will add to South African literature and as South Africa's market is highly regulated in terms of advertising, marketers will gain insight into this type of advertising in the country. This research paper aims to show that a number of factors influence shock advertising, and that the concept itself may not be as effective as people may think. This paper's main emphasis is that firms and marketers need to realise that alternative types of advertising are imperative if they want to hold the attention of consumers and begin to build positive relationships with their advertising.

\section{Limitations of this Study}

Due to time constraints, only five of Dahl, Frankenberger and Manchanda's (2003) seven types of shock were used (profanity/obscenity and vulgarity were not used). In order to get a true picture of shock advertising, it would have been better to use the full spectrum of types of shock. Focus groups, although time consuming, may have allowed for a clearer depiction of shock advertising with more insight and opinion over and above the administering of a questionnaire. Memory recall was only tested after an approximately two minute period, which may be too short. Being able to test 
memory recall after a day (or even a week) may be a better representation of memory recall. Using fictitious brands may have already put consumers at a disadvantage as they are unknown as brands to the consumer and perhaps by using existing brand names, consumers may be better able to relate to the brand.

\section{Areas of Future Research}

This paper has opened numerous opportunities for future research and for being able to expand and better understand the concept and intricacies of shock advertising. Further research can study the question of whether shock can be justified or not, and if whether it makes a difference or not in terms of ineffectiveness. For example, shock may be justified for societal causes because of the seriousness of the issue, for example, a women abuse advertisement displaying an abused woman which depicts the severity of the issue and that it should be prevented. This will test the question of whether it then makes the advertisement effective because of its intention or not. Future research should look at the difference between various age groups, for example, 12-18, 19-26, 27-35 and 35+ and see how results compare. Another measure that can be researched is behaviour over time and what the effects of shock do to the consumer in the long term. Other factors than can be researched are advertisement placement, in other words, does it make a difference where and in what context a consumer sees the advertisement as well if whether shock advertising leads to refusal to support the brand (opposite measures to purchase intention and sales). Comparisons can be performed where two advertisements are used to advertise the same product, with one of these containing shocking imagery. Consumers would be asked which is most effective, portrays the brand/message the best, leaves a lasting impression and would lead to purchase intention. Future research could perform studies with pre-existing advertisements or advertisements using real brands as opposed to fictitious brand names. Lastly, future research needs to be performed in order to give marketers practical alternatives to shock advertising which they can apply to their firms for example to break through the clutter, or remain unconventional but not within a controversial or shocking manner.

\section{Conclusion}

To conclude, the purpose of this article was to ascertain whether shock adverting is indeed losing its "shock" and becoming obsolete and ineffective. Three variables were analyzed, namely the level of shock, norm violation and memory recall, with five different types of shock (impropriety, moral offensiveness, sexual references, disgusting images and religious taboos). The moderating effects of these relationships with gender, religion and personal identity were also explored. The findings indicated that shock advertising has become obsolete, thus putting pressure on marketers to implement alternative methods to capture the attention of their target audience. As a result, shock advertising practically may no longer be fulfilling its true definition and may not hold the viability that marketers perceive it to possess.

\section{Reference List}

Alden, D. L., \& Crowley, A. E. (1995). Sex guilt and receptivity to condom advertising. Journal of Applied Social Psychology, 25, 1446-1463

An, D.C. \& Kim, S.H. (2006). Attitudes toward offensive advertising: a cross-cultural comparison between Korea and the United States, paper presented at the 2006 Annual Conference of the American Academy of Advertising, Reno, NV, March 30-April 2.

Andersson, S., Hedelin, A., Nilsson, A., \& Welander, C. (2004). Violent advertising in fashion marketing. Journal of Fashion Marketing and Management, 8(1), 96-112.

Bagozzi, R. P., \& Silk, A. J. (1983, Spring). Recall, Recognition, and the Measurement of Memory for Print Advertisements. Marketing Science, 2(2), 95-134.

Baron, R.A., \& Byrne, D. (1977). Social Psychology: Understanding Human Interaction. Boston, MA: Allyn and Bacon, Inc.

Berkowitz, L. (1984). Some effects of thoughts on anti-social and prosocial influences of media effects: A cognitive-neoassociation analysis. Psychological Bulletin, 95, 410-427.

Bushman, B. J. (2007). That Was a Great Commercial, but What Were They Selling? Effects of Violence and Sex on Memory for Products in Television Commercials. Journal of Applied Social Psychology, 37(8), 1784-1796.

Bushman, B. J., \& Bonacci, A. M. (2002). Violence and Sex Impair Memory for Television Ads. Journal of Applied Psychology, 87(3), 557-564.

Bushman, B. J., \& Phillips, C. M. (2001, April). If the Television Program Bleeds, Memory for the Advertisement Recedes. Current Directions in Psychological Science, 10(2), 43-47.

Castellon, J. P. (2006, September 20). Shockvertising: Does it work? Retrieved April 4, 2012, from Marketplace 21: http://marketplace21.wordpress.com/2006/09/20/shockvertising-does-it-work

Chan, K., Li, L., Diehl, S., \& Terlutter, R. (2007). Consumers' response to offensive advertising: a cross cultural study. International Marketing Review, 24(5), 606-628.

Colyer, E. (2002, March 18). Offensive but effective? Retrieved April 12, 2012, from Brand Channel: http://www.brandchannel.com Ifeatures_effect.asp?pf_id=84

Dahl, D. W., Frankenberger, K. D., \& Manchanda, R. V. (2003, September). Does It Pay to Shock? Reactions to Shocking and Nonshocking Advertising Content among University Students. Journal of Advertising Research, 268-280. 
Day, L.A. (1991). Ethics in Media Communications. Belmont, CA: Wadsworth.

De Pelsmacker, P., \& Geuens, M. (1996). The communication effects of warmth, eroticism, and humor in alcohol advertisements. Journal of Marketing Communications, 2, 247-262

Dubreuil, B. (2010, March). Punitive emotions and norm violations. Philosophical Explorations, 13(1), 35-50.

Duff, M. (1999). Gen Y comes of age: The 20s. Discount Store News, 38 (20), 39, 58.

Edell, J. A., \& Burke, M. C. (1987). The Power of Feelings in Understanding Advertising Effects. Journal of Consumer Research, 14, 421-433.

Eisenberg, N. (2000). Emotion, regulation, and moral development. Annual Review of Psychology, 51, 665-697.

Ellis, H.C., Thomas, R.L., \& Rodriguez, I.A. (1984). Emotional mood states and memory: Elaborative encoding, semantic processing, and cognitive effort. Journal of Experimental Psychology: Learning, Memory and Cognition, 10, 470-482.

Fessler, D.M.T., and Haley, K.J. (2003). The strategy of affect: Emotions in human cooperation. In The genetic and cultural evolution of cooperation, ed. P. Hammerstein, 7-36. Cambridge, MA: MIT Press.

Harrison, P. (2011, November 1). When advertising is shocking. Retrieved April 11, 2012, from Tribalinsight: http://tribalinsight.wordpress.com /2011/01/11/when-advertising-is-shocking/

Heath, R. \& Feldwick, P. (2008). Fifty years using the wrong model of advertising. International Journal of Market Research, 50(1), 29-60.

Heath, R., \& Nairn, A. (2005, April). Measuring Affective Advertising: Implications of Low Attention Processing on Recall. School of Management, University of Bath.

Heywood, J.L. (2002). The cognitive and emotional components of behavior norms in outdoor recreation. Leisure Science, 24(3/4), $271-281$.

Huhmann, B. A., \& Mott-Stenerson, B. (2008, September). Controversial advertisement executions and involvement on elaborative processing and comprehension. Journal of Marketing Communications, 14(4), 293-313.

Hunt, R. R., \& Ellis, H. C. (1999). Fundamentals of cognitive psychology (6th ed.). Dubuque, IA: McGraw-Hill College.

Jarlbro, G. (1994). Ungdomar tolkar reklam, rapport 1994/95:3. Konsumentverket. Stockholm.

Javed, M. B., \& Zeb, H. (2011). Good Shock or Bad Shock: What impact shock advertisements are creating on the mind of viewers. The Center for Innovation in Business and Management Practice, 1-12.

Jones, M. Y., Stanaland, A. S., \& Gelb, B. D. (1998, Summer). Beefcake and cheesecake: Insights for advertisers. Journal of Advertising, 27.

Kahneman, D. (1973). Attention and effort. Englewood Cliffs, NJ: Prentice Hall

Kapner, S. (1997). Understanding. Restaurant Business, July 15.

Keltner, D.Y.R. and Buswell, B.N. (1997). Embarrassment: its distinct form and appeasement function,. Psychological Bulletin, 122(3), $250-270$.

Klara, R. (2012, February 20). Advertising's Shock Troops. Adweek, 53(7), pp. 26-27 Hodge, M. (2007, April). Pushing The Brand Boundaries. NZ Marketing Magazine, 26(3), p. 11.

Lightfoot, G., Lilley, S., \& Kavanagh, D. (2006). The End of the Shock of the New. Journal of Creativity and Innovation Management, 15(2), 157-163.

MacDonald, F. (2008, April 13). Over the shock treatment. Sunday Star-Times, p. 13.

Malhotra, N. K., \& Birks, D. F. (2006). Marketing Research: An Applied Approach (Updated Second European Edition ed.). Harlow, Essex, England: Pearson Education Limited.

Manceau, D. \& Tissier-Desbordes, E. (2006). Are sex and death taboos in advertising?. International Journal of Advertising, 25(1), 9-33.

Merriam-Webster. (2013). ineffective. Retrieved May 24, 2013, from Merriam-Webster: http://www.merriam-webster.com/dictionary/ineffective Merriam-Webster. (2013). obsolete. Retrieved May 24, 2013, from Merriam-Webster Dictionary: http://www.merriam-webster.com/dictionary/obsolete Morris, W.N., \& Reilly, N.P. (1987). Towards the self-regulation of mood: Theory and research. Motivation and Emotion, 11, 215-249

Neuborne, E \& Kerwin, K. (1999). Generation Y. Business Week, Feb 15.

Oxford University Press. (2013). ineffective. Retrieved May 24, 2013, from Oxford Dictionaries: http://oxforddictionaries.com/definition/english/ineffective Oxford University Press. (2013). obsolete. Retrieved May 24, 2013, from Oxford Dictionaries: http://www.merriam-webster.com/dictionary/obsolete Pesquera, A. (2005), Reaching Generation Y. San Antonio Express-Newsz, 29, 1.

Peterson, K. (2004). Savvy Gen Y isn't buying traditional sales pitches. The Seattle Times, May, 17.

Pickton, D. \& Broderick, A., (2005). Integrated Marketing Communications (2nd ed). Pearson Education Limited, Edinburgh, UK.

Prendergast, G., Ho, B., \& Phau, I. (2002, September). A Hong Kong view of offensive advertising. Journal of Marketing Communications, 8(3), 165-177.

Sabri, O. (2012). Preliminary investigation of the communication effects of "taboo" themes in advertising. European Journal of Marketing, 46(1/2), 215-236.

Sandıkcı, Ö. (2011). Shock Tactics in Advertising and Implications for Citizen-Consumer. International Journal of Humanities and Social Science, 1(18), $42-$ 50.

Schlinger, M. (1979). A Profile of Response to Commercials. Journal of Advertising Research, 19, 37-46.

Schwartz, S. (2001). Sexy Dior billboard to vanish. Hong Kong Mail. 8 February, A05

Sherif, M. \& Sherif C.W. (1969). Social Psychology. New York: Harper \& Row.

Söderlund, M., \& Dahlén, M. (2010). The "killer" ad: an assessment of advertising violence. European Journal of Marketing, 44(11), $1811-1838$.

Spangenberg, E. R., Voss, K. E., \& Crowley, A. E. (1997). Measuring the Hedonic and Utilitarian Dimensions of Attitude: A Generally Applicable Scale. Advances in Consumer Research, 24, 235-241.

Thirteen complaints made to CTI's TVC (trans.). Apple Daily 26 March 1999, A06.

Tilles, D. (1998). DDB France pulls religious VW ads. Adweek 39(7), 5.

Valentine, D.B., \& Powers, T.L. (2013). Generation Y values and lifestyle segments. Journal of Consumer Research, 30(7). 597-606.

Waller, D. S. (2004). What Factors Make Controversial Advertising Offensive?: A Preliminary Study. ANZC A04 Conference (pp. 1-10). Sydney: University of Technology, Sydney, Australia.

Watson, D., Clark, L. A., \& Tellegen, A. (1988). Development and Validation of Brief Measures of Positive and Negative Affect. Journal of Personality and Social Psychology, 54, 1063-1070.

Williams, M. (2009, April 24). Does shock advertising still work? Retrieved April 9, 2012, from Campaign: http://www.campaignlive.co.uk/analysis/900778/

Wolburg J.M., \& Pokrywczynski, J. (2001). A Psychographic Analysis of Generation Y College Students. Journal of Advertising Research, September/October, 33-52.

Wong, C.K. (2000). Sexual connotations in advertising. Next Magazine 1 June, 162-163. 